\title{
Degradation of 2,4,6-trinitrotoluene (TNT) from explosive wastewater using nanoscale zero-valent iron
}

\author{
Xin Zhang a , Yu-man Lin ${ }^{\mathrm{a}}$, Xaio-quan Shan ${ }^{\mathrm{b}}$, Zu-liang Chen ${ }^{\mathrm{a}, *}$ \\ a School of Chemistry and Materials Science, Fujian Normal University, Fuzhou 350007, Fujian Province, China \\ ${ }^{\mathrm{b}}$ Research Centre for Eco-Environmental Sciences, Chinese Academy of Sciences, PO Box 2871, Beijing 100085, China
}

\section{A R T I C L E I N F O}

\section{Article history:}

Received 9 March 2009

Received in revised form 25 January 2010

Accepted 28 January 2010

\section{Keywords:}

Nanoscale zero-valent iron

2,4,6-Trinitrotoluene (TNT)

Degradation

\begin{abstract}
A B S T R A C T
The degradation of 2,4,6-trinitrotoluene (TNT) in wastewater using nanoscale zero-valent iron (nZVI) was investigated. The results showed that $>99 \%$ TNT was degraded when the initial TNT concentration was $80 \mathrm{mg} \mathrm{L}^{-1}$ after degradation for $3 \mathrm{~h}$ by $5 \mathrm{~g} \mathrm{~L}^{-1}$ of $\mathrm{nZVI}$ at $\mathrm{pH} 4,40^{\circ} \mathrm{C}$ using a rotary oscillation incubator operating at $200 \mathrm{rpm}$. The Langmuir-Hinshelwood kinetics model fit the kinetics of TNT degradation by nZVI well. Fourier transform infrared (FT-IR) and ultraviolet-visible spectrophotometry showed that TNT was adsorbed on the surface of nZVI, and this reduced TNT in aqueous solution. X-ray diffraction (XRD) demonstrated that the surface of nZVI changed during the degradation of TNT.
\end{abstract}

(c) 2010 Elsevier B.V. All rights reserved.

\section{Introduction}

One explosive that is widely used for military and civil purpose all over the world is 2,4,6-trinitrotoluene (TNT) [1]. As a result of this ubiquitous use, residual TNT in both soil and groundwater have been detected $[2,3]$. The presence of TNT and its degradation products in the aquatic environment have been associated with adverse impacts on biological receptors and communities [3,4]. Thus, TNT has been listed as a significant pollutant to public health and aquatic life by the USEPA [5].

Currently, TNT contaminated water is treated by various methods, including activated carbon adsorption [6,7], oxidation with hydrogen peroxide/ozone [8], supercritical water oxidation [9], Fenton reagent oxidation [10] and photocatalytic oxidation [11,12]. These methods are all useful for the degradation of TNT. However, the residual products after treatments with these methods are still potentially harmful. The use of nanoscale zero-valent iron (nZVI) is an alternative that has been demonstrated to be effective for the treatment of many pollutants commonly encountered in groundwater [13]. Due to its nanoparticle size, large surface area, and high in situ reactivity [14], nZVI has a great potential in environmental application such as the remediation of contaminated soil, sediment, and groundwater [15]. Since nZVI can be transported effectively by groundwater and can be injected as sub-colloidal metal particles into contaminated soils, sediments, and aquifers [15], it can be used for the remediation of wastewater contaminated by chlorinated

\footnotetext{
* Corresponding author. Tel.: +86 591 83465689; fax: +86 59183465689

E-mail address: zlchen@fjnu.edu.cn (Z.-l. Chen).
}

hydrocarbon, such as reduction of chlorinated ethenes, chlorinated ethanes [16,17] and PCBs [18] as well as degradation of benzoquinone [19] and chlorophenol [20]. In addition, the removal of $\mathrm{Cr}(\mathrm{VI})$ and $\mathrm{Pb}(\mathrm{II})$ from water [21] while oxidizing $\mathrm{Fe}^{0}$ to goethite $(\alpha-\mathrm{FeOOH})$, and removal of $\mathrm{As}(\mathrm{V}), \mathrm{As}(\mathrm{III})$ and humic acid $[22,23]$ by adsorption of nZVI have been reported. Furthermore, zero-valent iron was used to reduce nitroaromatic compounds (NACs) in contaminated water and soil [24]. However, it is interesting to note that the studies on the degradation of TNT using nZVI are still limited. Despite their minuscule status, nanoscale particles may hold the potential to cost-effectively address some of the challenges of site remediation $[14,15]$.

Therefore, the aim of this paper was to study the degradation and degradation kinetics of TNT by nZVI. Fourier transform infrared (FT-IR), ultraviolet-visible spectrophotometric (UV-vis) and X-ray diffraction (XRD) studies were all used to provide insight into the degradation mechanism.

\section{Materials and methods}

\subsection{Instruments and reagents}

nZVI powder (purity >99\%) was purchased from Shenzhen Junye Nanomaterial Co. Ltd. (Shenzhen, China). The nZVI ranged in size from 0 to $60 \mathrm{~nm}$ with a mean size of $25 \mathrm{~nm}$ and a specific surface area of $40-60 \mathrm{~m}^{2} \mathrm{~g}^{-1}$. Industrial-grade TNT (purity of $>99 \%$ ) was provided by Fuan Chemical Plant (Fujian Province, China). All other chemicals used were of analytical reagent grade or better.

A known amount of TNT powder was dissolved in deoxygenated distilled water heated to $70^{\circ} \mathrm{C}$, and this dissolved TNT solution was 
stored in a brown reagent bottle in the dark at $4{ }^{\circ} \mathrm{C}$ for 3-5 days prior to use [25].

Batch experiments were conducted in $15 \mathrm{~mL}$ serum bottles with known amounts of nZVI and TNT stock solution. The degradation reaction was initiated by adding $80 \mathrm{mg} \mathrm{L}^{-1}$ TNT stock solution $(10 \mathrm{~mL})$ to a known amount of nZVI. The bottles were capped with Teflon Mininert valves and mixed on a rotary shaker in an incubator at different temperatures. At selected time intervals during the degradation of TNT by nZVI, three samples were taken and separated from the solution by centrifugation at $3500 \mathrm{rpm}$ for $5 \mathrm{~min}$, and after centrifugation 2-5 mL of the supernatant phase was withdrawn and the concentration of TNT was determined by spectrophotometry. The effects of nZVI dose, $\mathrm{pH}$ of initial TNT solution, and reaction temperature on degradation time were examined and optimized. Blank experiments (without nZVI) were carried out in parallel. Preliminary results showed that the adsorption loss onto plastic container walls and degradation of TNT without nZVI was negligible. All experiments were undertaken in triplicate.

\subsection{Analysis of TNT}

The concentration of TNT in aqueous solution was determined using a UV-vis spectrophotometer method as described in the following steps: TNT sample solution $(2-5 \mathrm{~mL})$ was diluted to $10 \mathrm{~mL}$ with distilled water, then $2 \mathrm{~mL}$ of $4 \% \mathrm{H}_{2} \mathrm{SO}_{4}$ (v/v water), $5 \mathrm{~mL}$ of $5 \% \mathrm{Na}_{2} \mathrm{SO}_{3}, 2 \mathrm{~mL}$ of $0.3 \%$ cetylpyridinium chloride (CPC) and $2 \mathrm{~mL}$ of $33 \%(\mathrm{v} / \mathrm{v}$ water) 2-diethylamino ethanol (DEAE) were successively added. Finally the mixture was diluted to $25 \mathrm{~mL}$ with distilled water and shaken to combine the mixture. TNT in solution was subsequently determined using a 722 UV-vis spectrophotometer at $466 \mathrm{~nm}$ where TNT had the maximum absorption [26]. FT-IR (Fourier-380FT-IR, America) and a XRD (X' Pert Pro MPD, Holland) spectrometer were used to examine both the initial industrial grade TNT, the degradation products of TNT and nZVI after use.

\section{Results and discussion}

\subsection{Degradation of TNT by $n Z V I$}

The effect of nZVI dosage on TNT degradation is shown in Fig. 1a, which suggested that the degradation efficiency of TNT by nZVI was increased as nZVI dosage increased. When the concentration of nZVI increased, the total specific surface area and active sites of nZVI in solution also increased, which favoured degradation of TNT $[27,28]$. For example, when the concentration of nZVI was at 1.0 , $2.0,3.0,5.0$ and $7.5 \mathrm{~g} \mathrm{~L}^{-1}$, the percentage of TNT degradation was $59 \%, 74.5 \%, 88.6 \%, 96.2 \%$, and $99.6 \%$, respectively, over 8 h. Fig. $1 \mathrm{a}$ also shows that the concentration of residual TNT in solution was $<0.1 \mathrm{mg} \mathrm{L}^{-1}$ when the concentrations of nZVI ranged from 5.0 to $7.5 \mathrm{~g} \mathrm{~L}^{-1}$. Since nZVI have nanoparticle sizes and the nanoparticles could agglomerate easily [22], the addition of nZVI into an aqueous solution of TNT made the mixed solution difficult to centrifuge and separate, hence, an nZVI dose of $5.0 \mathrm{~g} \mathrm{~L}^{-1}$ was used for the remainder of this study.

To test the effect of $\mathrm{pH}$ on the degradation of TNT, the initial solution $\mathrm{pH}$ was adjusted to 3.96, 4.90, 6.07, 9.00, and 10.01 using $0.1 \mathrm{M}$ $\mathrm{HCl}$ or $\mathrm{NaOH}$, and $5 \mathrm{~g} \mathrm{~L}^{-1}$ of nZVI was added to each solution. Subsequently, the mixture was shaken on a rotary shaker with $150 \mathrm{rpm}$ at $30^{\circ} \mathrm{C}$ for $8 \mathrm{~h}$. The rate of TNT degradation varied with $\mathrm{pH}$ and was faster under acidity condition (Fig. 1b). When the initial $\mathrm{pH}$
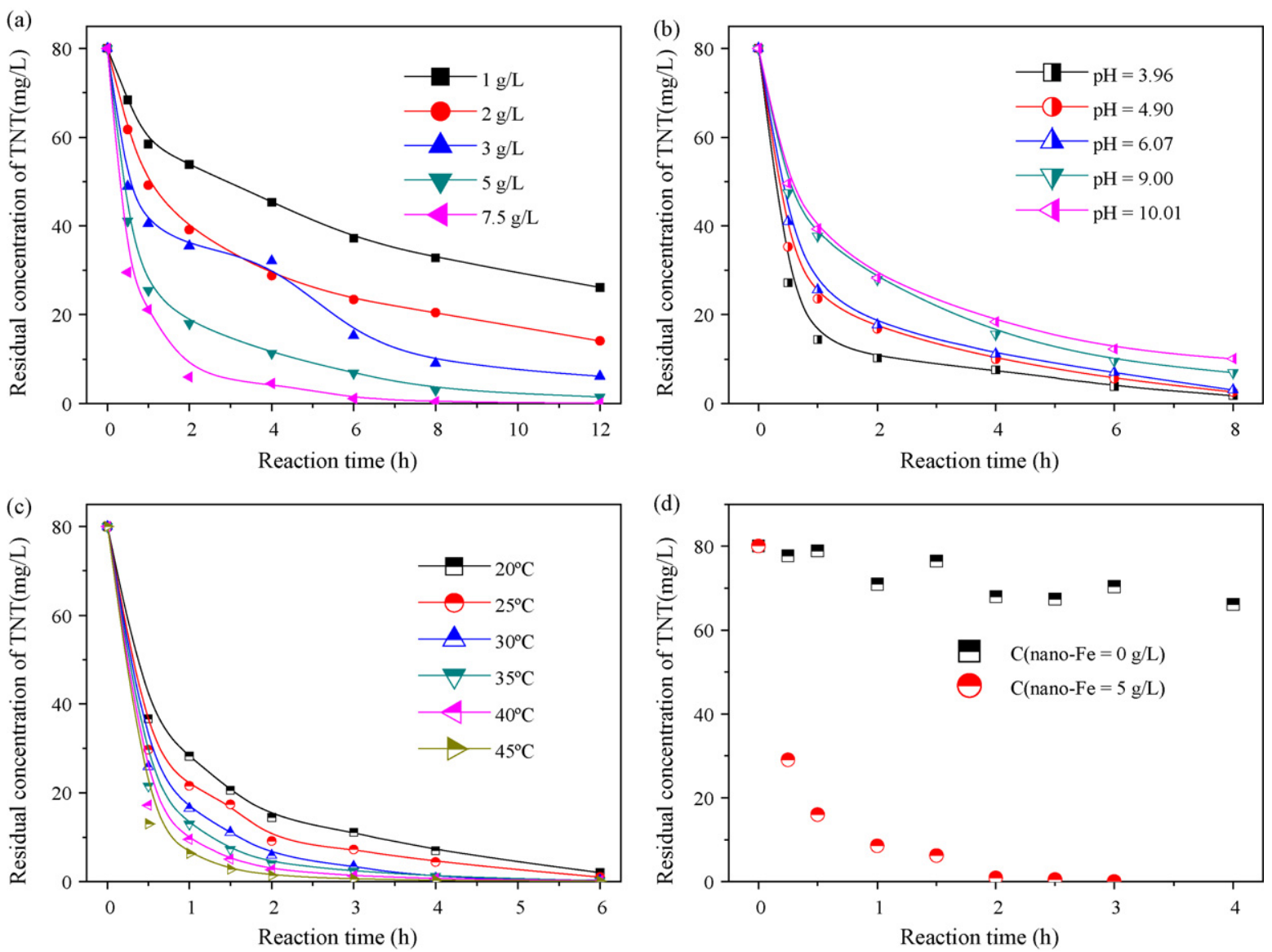

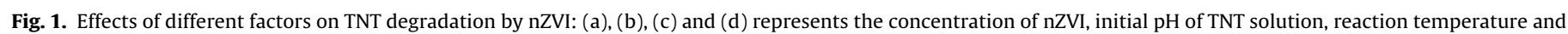
optimized conditions for the degradation of TNT, respectively. 


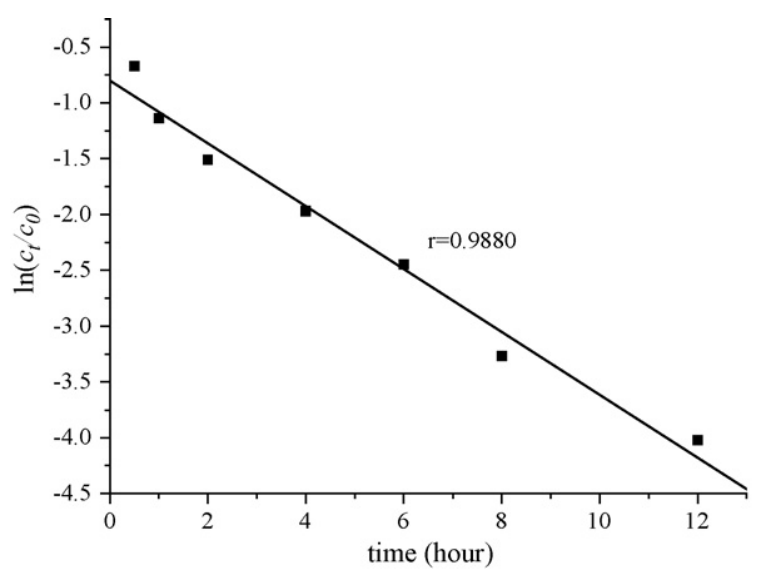

Fig. 2. The relationship between $\ln \left(C_{t} / C_{0}\right)$ and time.

was at $3.96,95.2 \%$ of the TNT was degraded within $6 \mathrm{~h}$, whereas only $84.7 \%$ of TNT was degraded under alkaline conditions during the same periods. Increased degradation of TNT under acidic conditions was due to increased amounts of hydrogen ions in solution, which could react with nZVI and produce new hydrogen with a higher reactive activity [29]. Consequently hydrogen ions accelerated the degradation of TNT [30]. In comparison, ferrous and ferric ions, produced by electrochemical corrosion of $\mathrm{Fe}^{0}$ [31], were prone to form hydroxide precipitates under alkaline conditions, which covered the surface of nZVI powders and reduced degradation reactions [19]. There was no significant difference in TNT degradation effectiveness when the degradation time was longer than $8 \mathrm{~h}$. An initial aqueous solution $\mathrm{pH}$ in the range of 4-6 was chosen as this was also compatible with the $\mathrm{pH}$ required for TNT determination via visible spectrophotometry.

The concentration of residual TNT at different degradation temperatures $\left(20,25,30,35,40\right.$ and $\left.45^{\circ} \mathrm{C}\right)$ is presented in Fig. 1c. Increased TNT degradation efficiency with increased temperature resulted from decreased active energies of either nZVI or TNT molecules at higher temperature [32]. Consequently, $40^{\circ} \mathrm{C}$ was chosen in this study.

On the basis of above studies the optimized degradation conditions were: $5 \mathrm{gL}^{-1} \mathrm{nZVI}, \mathrm{pH} 4$, and a degradation reaction temperature of $40^{\circ} \mathrm{C}$ if the initial TNT concentration was set at $80 \mathrm{mg} \mathrm{L}^{-1}$. There was a little decrease in the residual concentration of TNT in blank solutions within $4 \mathrm{~h}$ (Fig. 1d), while the residual concentration of TNT in the initial solution was a $<0.1 \mathrm{mg} \mathrm{L}^{-1}$ when $5 \mathrm{~g} \mathrm{~L}^{-1} \mathrm{nZVI}$ was present.

\subsection{Degradation kinetics}

Variation of selected experimental factors such as nZVI dose, $\mathrm{pH}$, and reaction temperature indicated that TNT degradation by nZVI could be optimized to effectively degrade TNT in aqueous solution. However, the degradation kinetics of TNT by nZVI was not known and need to be examined. To do this, aqueous solution of TNT were equilibrated with nZVI for various reaction times to determine degradation kinetics. A plot of the logarithm of residual TNT concentration versus degradation time was linear (Fig. 1a), and from linear regression (Fig. 2), it was concluded that the degradation of TNT by nZVI had pseudo-first order kinetics. Since the degradation of TNT occurred on the surface of nZVI, the Langmuir-Hinshelwood kinetics equation $[33,34]$ was used:

$v=-\frac{d C_{\mathrm{TNT}}}{d t}=k_{\mathrm{SA}} a_{\mathrm{s}} \rho_{\mathrm{m}}=k_{\mathrm{obs}} C_{\mathrm{TNT}}$ where $C$ is the TNT concentration $\left(\mathrm{mg} \mathrm{L}^{-1}\right)$ at time $t(\mathrm{~h}), k_{\mathrm{SA}}$ is the specific reaction rate constant based on the surface area of the nanoparticles $\left(\mathrm{Lh}^{-1} \mathrm{~m}^{-2}\right), a_{\mathrm{s}}$ is the specific surface area of the nanoparticles $\left(\mathrm{m}^{2} \mathrm{~g}^{-1}\right)$ and $\rho_{\mathrm{m}}$ is the mass concentration of the nanoparticles $\left(\mathrm{g} \mathrm{L}^{-1}\right)$. For a specific reaction, $k_{\mathrm{SA}}, a_{\mathrm{s}}$, and $\rho_{\mathrm{m}}$ are fixed, so Eq. (1) can be reduced to:

$k_{\mathrm{obs}}=k_{\mathrm{SA}} a_{\mathrm{s}} \rho_{\mathrm{m}}$

where $k_{\text {obs }}$ is the observed pseudo-first rate constant $\left(\mathrm{h}^{-1}\right)$. From Eqs. (1) and (2), formula (3) can be obtained based on the relationship of $\ln \left(C / C_{0}\right)$ and time:

$\ln \left(\frac{C}{C_{0}}\right)=-k t$

On the basis of our results, the degradation kinetics of TNT using nZVI is summarized in Eq. (3) and the degradation rate constant can be obtained by the slope of the linear regression slope from Fig. 2 $\left(0.31 \mathrm{~h}^{-1}\right)$.

\subsection{The degradation mechanism}

The mechanism of TNT degradation by nZVI involves complex surface chemistry during in situ corrosion of the nZVI surface, reduction of TNT to the degraded products through coupled oxidation of $\mathrm{Fe}^{0}$ and $\mathrm{Fe}^{2+}$ [31]. In this section, a possible degradation mechanism of TNT by nZVI was investigated using UV, FT-IR and $\mathrm{XRD}$ to provide insight into the structure of the TNT degradation and Fe reaction products.

In aqueous solution, oxidation of metallic $\mathrm{Fe}^{0}$ to ferrous ions by substances such as water and oxygen leads to the dissolution of solid iron, which is the primary cause of iron corrosion. Metallic corrosion is an electrochemical process in which oxidation of zerovalent iron to ferrous ions has the anodic half-reaction [31]

$\mathrm{Fe}^{0} \rightarrow \mathrm{Fe}^{2+}+2 \mathrm{e}^{-}$

TNT in a $\mathrm{Fe}^{0}-\mathrm{H}_{2} \mathrm{O}$ system accepts electrons donated by corrosion of nZVI and nitro groups are reduced [31]:<smiles></smiles>

In addition, ferrous ion and hydrogen molecule also provide electrons in the aqueous phase as described below:

$\mathrm{Fe}^{2+} \rightarrow \mathrm{Fe}^{3+}+\mathrm{e}^{-}$

$\mathrm{H}_{2} \rightarrow 2 \mathrm{H}^{+}+2 \mathrm{e}^{-}$

Eq. (4) is the primary of the three equations for donating electrons.

In the $\mathrm{Fe}^{0}-\mathrm{H}_{2} \mathrm{O}$ system, water and dissolved oxygen molecules may compete for available electrons according to the following half-reactions:

$\mathrm{H}_{2} \mathrm{O}+2 \mathrm{e}^{-} \rightarrow 2 \mathrm{OH}^{-}+\mathrm{H}_{2}$
$\mathrm{O}_{2}(\mathrm{~g})+2 \mathrm{H}_{2} \mathrm{O}+4 \mathrm{e}^{-} \rightarrow 4 \mathrm{OH}^{-}$

As described in Eq. (9), since oxygen accepts electrons this would hinder the reduction reaction of TNT in aqueous solution via competition for available electrons and it is therefore suggested that the degradation of TNT by nZVI should proceed better under anaerobic conditions.

As nZVI has high specific surface area and strong adsorption capacity, TNT molecules are absorbed on the surface of nZVI in 


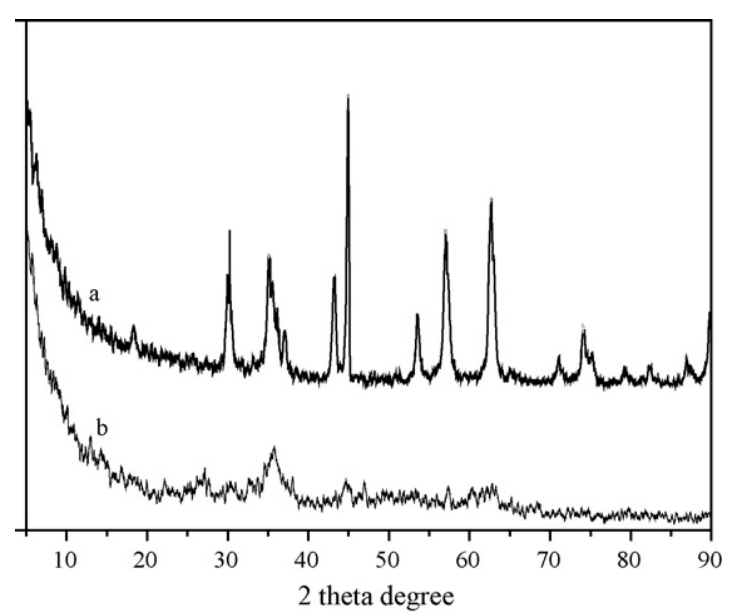

Fig. 3. XRD spectra of nanoscale $\mathrm{Fe}^{0}$ : (a) nZVI; (b) nZVI reacted with TNT.

aqueous system, and then adsorbed TNT accepts electrons donated by the nZVI powder corrosion, and hence TNT is reduced [31]:

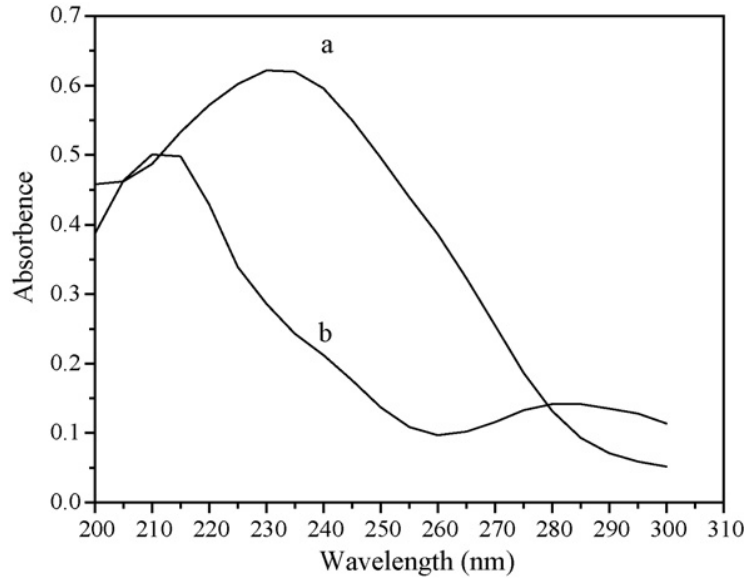

Fig. 5. Ultraviolet spectra of TNT solution: (a) TNT solution without nZVI; (b) degradation solution including reaction products.

degree) are attributed to magnetite-maghemite $\left(\mathrm{Fe}_{3} \mathrm{O}_{4} / \gamma-\mathrm{Fe}_{2} \mathrm{O}_{3}\right)$ and a peak at $63^{\circ}$ is attributed to lepidocrocite $(\gamma$-FeOOH) [35]. The

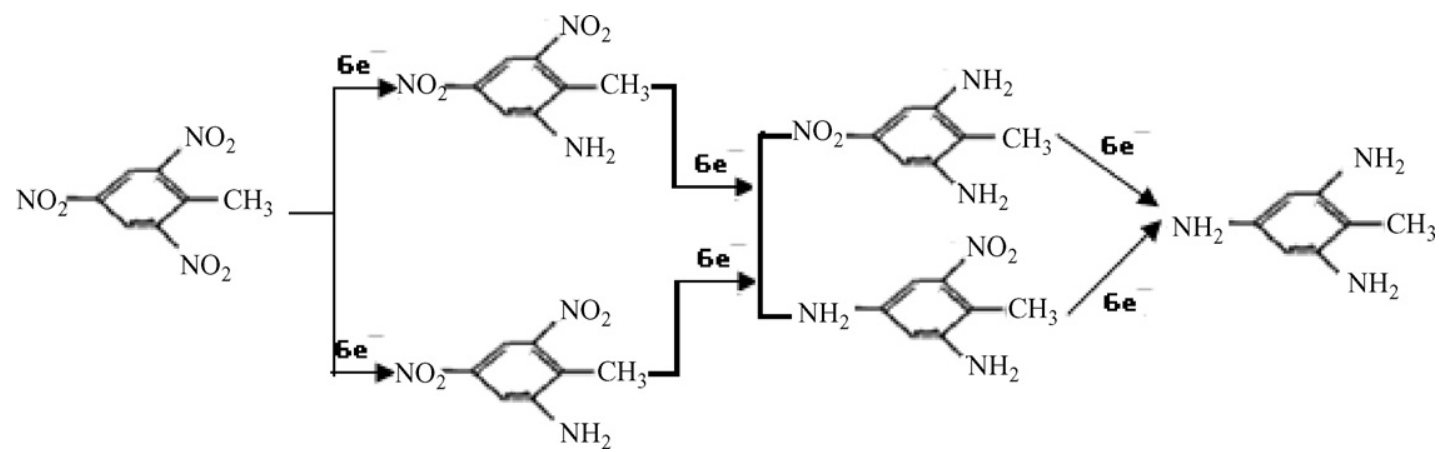

When nitro groups of TNT molecule are reduced to the amino group, 2,4,6-trinitrotoluene is reduced to aromatic amine compounds. Though aromatic amine compounds are still toxic, these amine compounds are biodegraded relatively easily [24].

XRD spectra of commercial nZVI exhibits peaks due toFe ${ }^{0}$ at 45, 65, 84 (2-theta degree) (Fig. 3a) which was consistent with nanosized $\mathrm{Fe}^{0}$ synthesized by $\mathrm{KBH}_{4}$ reducing $\mathrm{FeCl}_{3}$ [21]. These three peaks were found to have low intensity because of the presence of an amorphous iron phase. Peaks at 35, 37, 43, 67 (2-theta

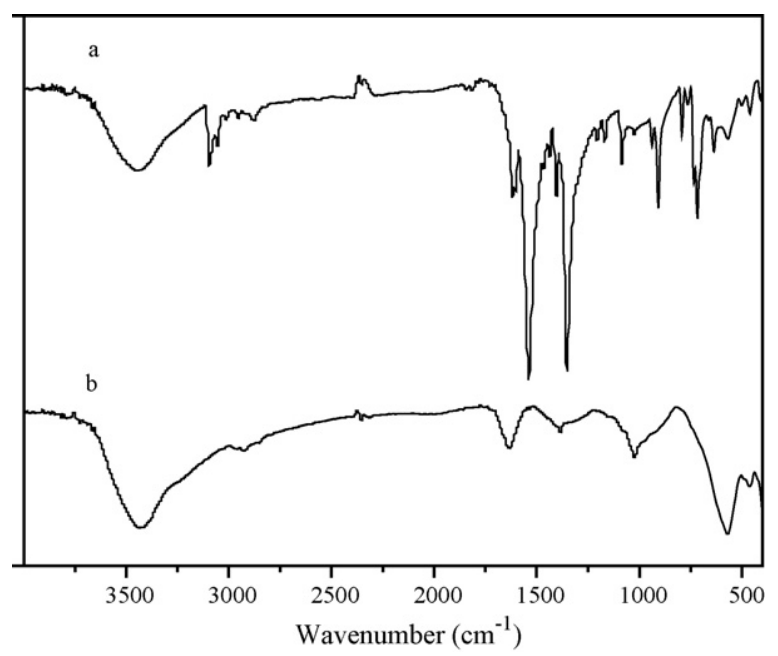

Fig. 4. FT-IR spectra of TNT and after degradation by nZVI: (a) TNT powders before degradation reaction; (b) nanoscale $\mathrm{Fe}^{0}$ including degradation products. existence of these peaks showed that nZVI had been partly oxidized because of passivation treatment by the company. The XRD spectra of nZVI after being used to reduce TNT under the optimal conditions showed that the three diffraction peaks of $\mathrm{Fe}^{0}$ became weaker and the amorphous phase appeared more, whereas peaks attributable to magnetite-maghemtie and lepidocrocite weakened or even disappeared (Fig. 3b).

Fig. 4 shows the FT-IR spectra of TNT and TNT-adsorbed nZVI. In Fig. 4b, a new strong adsorption peak appeared at $3427 \mathrm{~cm}^{-1}$, corresponding to the absorption peak of an amino group $\left(-\mathrm{NH}_{2}\right)$ indicating that the nitro group $\left(-\mathrm{NO}_{2}\right)$ had been reduced by $\mathrm{nZVI}$. This finding was supported by the disappearance of a strong absorption peak attributable to the nitro group $\left(-\mathrm{NO}_{2}\right)$ at $1352 \mathrm{~cm}^{-1}$ originally in Fig. 4a. Furthermore, TNT adsorbed on nZVI was reduced since the peak at $2962 \mathrm{~cm}^{-1}$ corresponded to adsorption peak of $\mathrm{C}-\mathrm{H}$ bond stretching vibration and peaks at $1631 \mathrm{~cm}^{-1}$, $1529 \mathrm{~cm}^{-1}$ and $1384 \mathrm{~cm}^{-1}$ corresponded to benzene skeleton (Fig. 4a).

Fig. 5 shows the UV spectra of TNT in solution with and without nZVI. The TNT absorption maxima peak at $230 \mathrm{~nm}$ [36], was shifted to lower wavelength after degradation and the intensity of this new maximum peak was also reduced further demonstrating that TNT in aqueous solution was at least partially reduced and degraded.

\section{Conclusion}

In this study the optimal conditions for degradation of TNT were $5 \mathrm{~g} \mathrm{~L}^{-1} \mathrm{nZVI}, \mathrm{pH} 4,40^{\circ} \mathrm{C}$ and $200 \mathrm{rpm}$ for an initial TNT concentration of $80 \mathrm{mg} \mathrm{L}^{-1}$. Under such conditions $>99 \%$ of TNT was degraded after $3 \mathrm{~h}$. In addition, the degradation reaction of TNT 
by nZVI followed the pseudo-first order reaction model, which was well described by Langmuir-Hinshelwood kinetics equation. Furthermore, XRD spectrum showing changes in nZVI did occur following degradation and FT-IR and UV spectra revealed that TNT was reduced.

\section{Acknowledgement}

This research was supported by a Fujian "Minjiang Fellowship" from Fujian Normal University.

\section{References}

[1] K.S. Ro, A. Venugopal, D.D. Adrian, D. Constant, K. Qaisi, K.T. Valsaraj, L.J. Thibodeaux, D. Roy, Solubility of 2,4,6-trinitrotoluene (TNT) in water, Chem. Eng. Data 41 (1996) 758-761.

[2] J.D. Nijs, M. Frank, Assessment of technologies for disposing explosive waste, J. Hazard. Mater. 90 (2002) 137-153.

[3] J.C. Pennington, J.M. Brannon, Environmental fate of explosives, Thermochim. Acta 384 (2002) 163-172.

[4] J.L. Conder, T.W. La Point, J.A. Steevens, G.R. Lotufo, Recommendations for the assessment of TNT toxicity in sediments, Environ. Toxicol. Chem. 23 (2004) $141-149$.

[5] USEPA, Health Advisory on Trinitrotoluene, Office of Drinking Water, Washington, DC, 1988.

[6] C. Rajagopal, J.C. Kapoor, Development of adsorptive removal process for treatment of explosives contaminated wastewater using activated carbon, J. Hazard. Mater. B87 (2001) 73-98.

[7] J.W. Lee, T.H. Yang, W.G. Shim, T.O. Kwon, I.S. Moon, Equilibria and dynamics of liquid-phase trinitrotoluene adsorption on granular activated carbon: effect of temperature and pH, J. Hazard. Mater. 141 (2007) 185-192.

[8] Y.G. Wu, J. Jiao, D.W. Zhao, Advanced oxidation processes for treatment of wastewater contaminated by explosives, J. Energetic Mater. 11 (2003)166-169.

[9] S.J. Chang, Y.C. Liu, Degradation mechanism of 2,4,6-trinitrotoluene in supercritical water oxidation, J. Environ. Sci. 19 (2007) 1430-1435.

[10] S.Y. Oh, P.C. Chiu, B.J. Kim, D.K. Cha, Enhancing Fenton oxidation of TNT and RDX through pretreatment with zero-valent iron, Water Res. 37 (2003) 4275-4283.

[11] H.S. Son, S.J. Lee, K.D. Zoh, Kinetics and mechanism of TNT degradation in $\mathrm{TiO}_{2}$ photocatalysis, Chemosphere 57 (2004) 309-317.

[12] D.C. Schmelling, K.A. Gray, Photocatalytic transformation and mineralization of 2,4,6-trinitrotoluene (TNT) in $\mathrm{TiO}_{2}$ slurries, Water Res. 29 (1995) 2651-2662.

[13] X.Q. Li, D.W. Elliott, W.X. Zhang, Zero-valent iron nanoparticles for abatement of environmental pollutants: materials and engineering aspects, Crit. Rev. Solid State Mater. Sci. 31 (2006) 111-122.

[14] W.X. Zhang, Nanoscale iron particles for environmental remediation: an overview, Nanopart. Res. 5 (2003) 323-332.

[15] D.W. Elliott, W.X. Zhang, Field assessment of nanoscale bimetallic particles for groundwater treatment, Environ. Sci. Technol. 35 (2001) 4922-4926.

[16] H.L. Lien, W.X. Zhang, Nanoscale iron particles for complete reduction of chlorinated ethenes, Colloids Surf. 191 (2001) 97-105.
[17] H.L. Lien, W.X. Zhang, Hydrodechlorination of chlorinated ethanes by nanoscale Pd/Fe bimetallic particles, J. Environ. Eng. 131 (2005) 4-10.

[18] C.B. Wang, W.X. Zhang, Synthesizing nanoscale iron particles for rapid and complete dechlorination of TCE and PCBs, Environ. Sci. Technol. 31 (1997) 2154-2156.

[19] J.T. Nurmi, Characterization and properties of metallic iron nanoparticles: spectroscopy, electrochemistry, and kinetics, Environ. Sci. Technol. 39 (2005) 1221-1230.

[20] R. Cheng, J.L. Wang, W.X. Zhang, Comparison of reductive dechlorination of p-chlorophenol using $\mathrm{Fe}^{0}$ and nanosized $\mathrm{Fe}^{0}$, J. Hazard. Mater. 144 (2007) 334-339.

[21] S.M. Ponder, J.G. Darab, T.E. Mallouk, Remediation of $\mathrm{Cr}(\mathrm{VI})$ and $\mathrm{Pb}(\mathrm{II})$ aqueous solutions using nanoscale zero-valent iron, Environ. Sci. Technol. 34 (2000) 2564-2569.

[22] S.R. Kanel, J.M. Greneche, H. Choi, Arsenic (V) removal from groundwater using nanoscale zero-valent iron as a colloidal reactive barrier material, Environ. Sci. Technol. 40 (2006) 2045-2050.

[23] S.R. Kanel, B. Manning, L. Charet, H. Choi, Removal of arsenic(III) from groundwater by nanoscale zero-valent iron, Environ. Sci. Technol. 39 (2005) 1291-1298.

[24] L.S. Hundal, J. Singh, E.L. Bier, P.J. Shea, S.D. Comfort, W.L. Powers, Removal of TNT and RDX from water and soil using iron metal, Environ. Pollut. 97 (1997) 55-64.

[25] R.T. Upson, S.E. Burns, Sorption of nitroaromatic compounds to synthesized organoclays, J. Colloid Interface Sci. 297 (2006) 70-76.

[26] GB/TI3905-92, Analysis method on trinitrotoluene in aqueous solution-sodium sulfite spectrophotometry [S].

[27] F. He, D.Y. Zhao, Preparation and characterization of a new class of starchstabilized bimetallic nanoparticles for degradation of chlorinated hydrocarbons in water, Environ. Sci. Technol. 39 (2005) 3314-3320.

[28] Y.Q. Liu, S.A. Majetich, R.D. Tilton, TCE dechlorination rates, pathways, and efficiency of nanoscale iron particles with different properties, Environ. Sci. Technol. 39 (2005) 1338-1345.

[29] H. Zhang, Z.H. Jin, L. Han, Synthesis of nanoscale zero-valent iron supported on exfoliated graphite for removal of nitrate, Trans. Nonferrous Met. Soc. China 16 (2006) 345-349.

[30] Y.Q. Liu, G.V. Lowry, Effect of particle age ( $\mathrm{Fe}^{0}$ Content) and solution $\mathrm{pH}$ on NZVI reactivity: $\mathrm{H}_{2}$ evolution and TCE dechlorination, Environ. Sci. Technol. 40 (2006) 6085-6090.

[31] S.H. Choe, S.H. Lee, Y. Chang, Rapid reductive destruction of hazardous organic compounds by nanoscale $\mathrm{Fe}^{0}$, Chemosphere 42 (2001) 367-372.

[32] F.Y. Chen, Y.B. Tang, X.W. Lv, Study on reduction kinetics of $\mathrm{Cr}(\mathrm{VI})$ in water by nanoscale zero-valent iron, Chem. World 48 (2007) 144-147.

[33] R.W. Gllham, S.F. O'Hannesin, Enhanced degradation of halogenated aliphatics by zero-valent iron, Ground Water 32 (1994) 958-967.

[34] W.A. Arnokl, A.L. Roberts, Pathways and kinetics of chlorinated ethylene and chlorinated acetylene reaction with $\mathrm{Fe}(0)$ particles, Environ. Sci. Technol. 34 (2000) 1794-1805.

[35] Y.P. Sun, X.Q. Li, J.S. Cao, Characterization of zero-valent iron nanoparticles, Adv. Colloid Interface Sci. 20 (2006) 47-56.

[36] S.B. Li, S.S. Rao, W. Wang, Determination of TNT Detonating Explosive Wastewater by Direct Ultraviolet Photometric Analysis, Chinese J. Spectrom. Lab. 21 (2004) 1024-1027. 